\title{
Revisiting the 23 February 1892 Laguna Salada Earthquake
}

\author{
by Susan E. Hough and Austin Elliot
}

\begin{abstract}
According to some compilations, the Laguna Salada, Baja California, earthquake of 23 February 1892 ranks among the largest earthquakes in California and Baja California in historic times. Although surface rupture was not documented at the time of the earthquake, recent geologic investigations have identified and mapped a rupture on the Laguna Salada fault that can be associated with high probability with the 1892 event (Mueller and Rockwell, 1995). The only intensity-based magnitude estimate for the earthquake, $M 7.8$, was made by Strand (1980) based on an interpretation of macroseismic effects and a comparison of isoseismal areas with those from instrumentally recorded earthquakes. In this study we reinterpret original accounts of the Laguna Salada earthquake. We assign modified Mercalli intensity (MMI) values in keeping with current practice, focusing on objective descriptions of damage rather than subjective human response and not assigning MMI values to effects that are now known to be poor indicators of shaking level, such as liquefaction and rockfalls. The reinterpreted isoseismal contours and the estimated magnitude are both significantly smaller than those obtained earlier. Using the method of Bakun and Wentworth (1997) we obtain a magnitude estimate of $M 7.2$ and an optimal epicenter less than $15 \mathrm{~km}$ from the center of the mapped Laguna Salada rupture. The isoseismal contours are elongated toward the northwest, which is qualitatively consistent with a directivity effect, assuming that the fault ruptured from southeast to northwest. We suggest that the elongation may also thus reflect wave propagation effects, with more efficient propagation of crustal surface $(L g)$ waves in the direction of the overall regional tectonic fabric.
\end{abstract}

\section{Introduction}

Southern California and northern Baja California were relatively sparsely populated in the 1890 s. Nonetheless, the earthquake of 23 February 1892 was strongly felt and documented in many locations throughout southern California. While surface rupture had been mapped following an 1887 earthquake in northern Sonora, Mexico (DuBois and Smith, 1980), the remote epicentral region of the 1892 event was apparently never investigated at the time of the earthquake. Based on the distribution of shaking effects, Strand (1980) concluded that the earthquake most likely originated on the Laguna Salada fault, along which very recent scarps had been documented (Barnard, 1968). Mueller and Rockwell (1995) mapped a 22-km segment of Holocene obliquedextral rupture along the Laguna Salada fault in northern Baja California (Fig. 1); they also documented a small component of normal rupture on the nearby northeast-striking Canon Rojo fault. Based on the observed rupture length and scarps with 3-4 m of vertical displacement, Mueller and Rockwell (1995) estimated a moment magnitude of 7.1. They noted that slip might have extended an additional 10 $\mathrm{km}$ farther south; the rupture might also have extended farther north, into an area that is covered by young sand dunes.
The $M_{\mathrm{w}}$ estimate of 7.1 was thus considered a lower bound. Based on scarp degradation relationships, they further estimated that the earthquake occurred within the past 100-200 yr. They associated the rupture with the known historic event on 23 February 1892, which had been previously estimated to be located farther west (Toppozada et al., 1981).

In an exhaustive archival search, Strand (1980) compiled nearly 100 original accounts of the earthquake, primarily from newspaper accounts but also from other sources such as letters. Strand (1980) also compiled accounts from one foreshock and several of the larger aftershocks. In this study we focus on only the mainshock. In his study, Strand (1980) interpreted these accounts to obtain modified Mercalli intensity (MMI) values (Table 1). In his interpretations he followed the scheme of Brazee (1979), who compiled lists of detailed indicators for each MMI level. In his interpretation, Strand (1980) generally assigned MMI values based on the indicator(s) that corresponded to the highest intensity level. For example, an MMI value of VI was assigned to Los Angeles $\left(34: 03^{\circ} \mathrm{N}, 118: 15^{\circ} \mathrm{W}\right)$ based on accounts that described only modest objective effects, such as the swaying of chandeliers, but also alarm and nausea on the part of some 


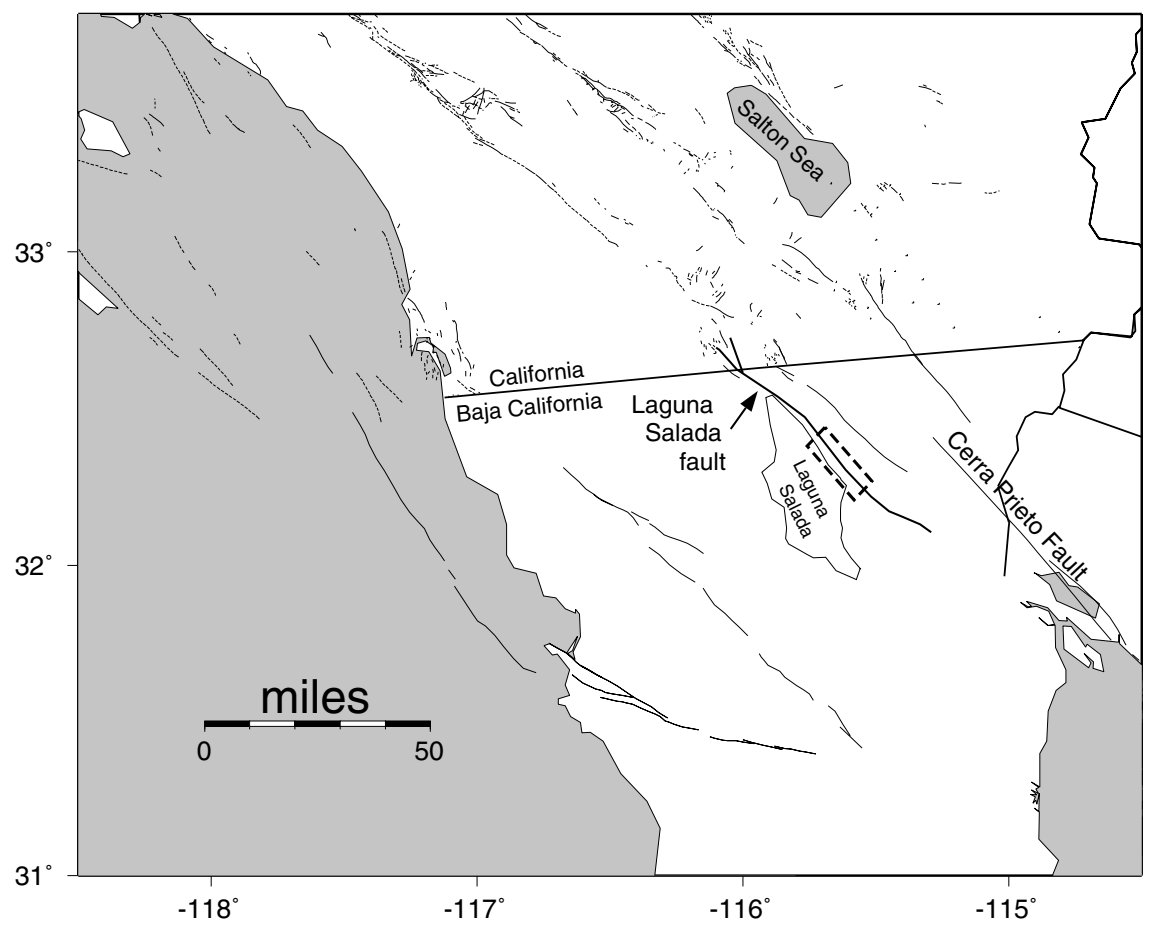

Figure 1. Map of northern Baja California and southern California. Location of Holocene surface rupture identified by Mueller and Rockwell (1995) is indicated by dashed box. Mapped faults, in this and other maps, are from Jennings (1994).

observers. Strand (1980) also assigned a number of high MMI values $(\mathrm{VIII}+)$ based on accounts that described rockfalls, liquefaction, changes in water level, and so on. Many of these accounts were from remote desert regions in and around the Salton Trough, where no (or very few) buildings existed at the time. For example, at Storm Canyon (32:55 $\left.\mathrm{N}, 116: 26^{\circ} \mathrm{W}\right)$ an account described rockfalls and the drying up of a small spring; MMI VII + was assigned to this account.

Strand's (1980) interpretations differ from the current practice of intensity determinations in two critical respects. First, especially in modern analyses, such as those implemented by the U.S. Geological Survey Community Internet Intensity Mapping project (Wald et al., 1999), MMI values are assigned based on the overall effects at a location rather than the most severe reported effects. Hough et al. (2000) argued that this approach is especially important to avoid overemphasis of subjective human response (people frightened, etc.) during large regional earthquakes, for which shaking can be dramatic even when damage is very low.

A second difference between our approach and that of Strand (1980) reflects the growing awareness that certain indicators do not reflect reliably the level of shaking at a site. Such indicators include rockfalls, liquefaction, and waterlevel changes in wells (e.g., Ambraseys and Bilham, 2003). Formerly, for example, liquefaction was sufficient to assign MMI values of at least VIII, whereas recent studies have documented liquefaction in earthquakes as small as $M 3.5$, for which MMI cannot have been above perhaps V (Musson, 1998). The distribution of rockfalls will moreover largely correspond to the distribution of rocks, some of which will fall in response to low levels of shaking (as, in fact, some rockfalls occur in the absence of shaking). Unfortunately, because northern Baja California was so sparsely populated in 1892, many of the relatively close-in accounts do not include any information about damage to structures. We were thus able to assign intensity values for only 74 of the 98 locations at which intensities were assigned by Strand (1980); we also assign not-felt values for three locations at which it was reported that the earthquake was not felt. These 77 values provide reasonably good coverage of the intensity field throughout southern California (Fig. 2). Figure 2 also indicates locations at which landslides and rockfalls were observed; we will discuss these results in a later section.

The isoseismal contours shown in Figure 2 were calculated by the gridding algorithm used in the surface utility of the Generic Mapping Tools (Wessel and Smith, 1991). This algorithm uses a tension factor, $T$, to control the degree of curvature. The minimum curvature solution, $T=0$, can generate unrealistic oscillations, while $T=1$ will generate a solution with no maxima or minima away from control points. Here we use $T=0.5$, which allows the algorithm to find a maximum in the near-field region. As shown in Figure 2 , the global maximum is found to be at the southern end of the Laguna Salada rupture as mapped by Mueller and Rockwell (1995). 
Table 1

Accounts and Intensities of the Laguna Salada Earthquake

\begin{tabular}{|c|c|c|c|c|c|c|}
\hline Location & Latitude $(\mathrm{N})$ & Longitude (W) & Map & Table & Rev. MMI & Most severe reported effects \\
\hline Alpine & 32.833 & -116.767 & 7 & 7 & 5 & Many frightened, rumblings like carriage \\
\hline Anaheim & 33.833 & -117.917 & 6 & 6 & 4 & Hanging objects swung, felt by almost all \\
\hline Bakersfield & 35.357 & -119.004 & & & 1 & Not felt \\
\hline Ballast Point Light Station & 33.683 & -117.233 & 7 & 6 & 4 & Clocks stopped, duration estimated \\
\hline Banning & 33.933 & -116.867 & 4 & 5 & 4 & Described as strong \\
\hline Barret Valley & 32.617 & -116.700 & 7 & 7 & 5 & All frightened, loud sounds \\
\hline Beaumont & 33.933 & -116.983 & 5 & 5 & 4 & Hanging pictures displaced, liquids sloshed \\
\hline Bernardo & 33.033 & -117.050 & 7 & 6 & 5 & Described as strong \\
\hline Boyle Heights & 34.033 & -118.200 & 5 & 5 & 5 & Small objects moved, animals frightened \\
\hline Bratton Valley & 32.683 & -116.750 & 7 & 7 & 6 & Rockfalls, difficult to stand \\
\hline Buckman Springs & 32.767 & -116.483 & 8 & 7 & 6 & Changes in wells/springs, loud sound \\
\hline Cameron Corners & 32.633 & -116.467 & 8 & $7+$ & & All frightened \\
\hline Campo & 32.600 & -116.483 & 8 & 8 & 7 & Some damage to poorly built masonry \\
\hline Carrizo Station & 32.883 & -116.050 & 9 & $8+$ & 8 & Damage to poorly built masonry \\
\hline Carson City, Nevada & 39.167 & -119.767 & & $1-$ & 1 & Not felt \\
\hline Cerro Prieto Mud Volcano Region, Baja & 32.400 & -115.267 & 9 & $9+$ & 7.5 & Alarm/panic, groundwater ejected \\
\hline Chino & 34.017 & -117.700 & 6 & 6 & 5 & Felt by all, some furniture jostled \\
\hline Chocolate Canyon & 32.867 & -116.783 & 7 & $6+$ & 4 & Roaring sounds, rumblings like carriage \\
\hline Claremont & 35.000 & -117.800 & 6 & 6 & & Many frightened \\
\hline Colorado Desert & & & 10 & $10+$ & 7 & Fissures in ground, alarm/panic \\
\hline Colton & 34.667 & -117.350 & 7 & 6 & & Many ran outdoors, many frightened \\
\hline Coronado & 32.631 & -117.174 & 7 & 6 & 5 & Liquids sloshed, many frightened \\
\hline Cuyamaca & 33.000 & -116.567 & 7 & 8 & & Waves seen on surface of ground \\
\hline Dehesa & 32.783 & -116.850 & 7 & 7 & 6 & All frightened, landslides, loud sound \\
\hline Devil's Canyon & 32.683 & -116.050 & 9 & $8+$ & 6 & Landslides, loud sound \\
\hline Downey & 33.933 & -118.100 & 5 & 5 & 4 & Clocks stopped, described as strong \\
\hline Duarte & 34.133 & -117.983 & 4 & 4 & 3 & Described as light, direction of motion noted \\
\hline Dulzura & 32.650 & -116.783 & 7 & 7 & 6 & Changes in springs/wells \\
\hline Dulzura Canyon & 32.650 & -116.800 & 7 & 7 & 7 & Landslides, waves seen on ground \\
\hline El Alamo, Baja & 31.600 & -116.050 & 7 & 6 & 5 & Described as strong \\
\hline El Cajon & 32.783 & -116.967 & 7 & 7 & 7 & Cracks in ground, ground slumping \\
\hline Elsinore & 33.667 & -117.333 & 6 & 6 & & All awakened \\
\hline Encinitas & 33.500 & -117.300 & 6 & 5 & & Animals frightened \\
\hline Ensenada, Baja & 31.867 & -116.600 & 7 & 7 & 5 & Liquids sloshed, small objects fell \\
\hline Escondido & 33.117 & -117.100 & 7 & 7 & 5.5 & Spring/well changes, liquids sloshed \\
\hline Fairview & 33.283 & -117.233 & 6 & 6 & 4 & Described as strong \\
\hline Flinn Ranch & 32.850 & -116.850 & 7 & 7 & & Spring/well changes \\
\hline Fullerton & 33.867 & -117.900 & 6 & 7 & 6 & Slight damage to weak masonry, objects fell \\
\hline Hesperia & 34.417 & -117.300 & 4 & 4 & 3 & Described as light, direction indicated \\
\hline Highlands & & & 7 & $6+$ & 5 & Many ran outdoors (EQ lights reported) \\
\hline Hook Ranch & 32.700 & -116.500 & 8 & 8 & 8 & Trees shaken violently, people thrown off feet \\
\hline Hupah Flats & 33.100 & -116.300 & 8 & $7+$ & & Spring/well changes \\
\hline Indio & 33.733 & -116.233 & 7 & $6+$ & 5 & Many frightened \\
\hline Jacumba & 32.617 & -116.183 & 9 & 9 & & Alarm/panic, spring/well changes \\
\hline Jamul & 32.717 & -116.867 & 7 & 7 & 6 & Cracks in masonry walls \\
\hline Jewel Valley & 32.633 & -116.267 & 9 & 9 & 8 & Damage to weak masonry, ground cracked \\
\hline Julian & 33.083 & -116.567 & 7 & 7 & 5 & Small objects overturned \\
\hline Laguna Station & 32.767 & -115.750 & 10 & $9+$ & 7.5 & Alarm/panic, people thrown off feet \\
\hline Lancaster & 34.693 & -118.176 & & & 1 & Not felt \\
\hline Lawson Valley & 33.750 & -116.783 & 7 & $6+$ & 6 & Furniture jostled \\
\hline Long Beach & 33.767 & -118.183 & 5 & & & \\
\hline Los Angeles & 34.050 & -118.250 & 5 & 6 & 5.5 & Many frightened, plaster fell \\
\hline McCain Valley & 32.767 & -116.333 & 9 & 9 & 8 & Damage to weak masonry, visible ground waves \\
\hline Moreno Valley & 32.717 & -116.533 & 8 & $7+$ & & Wet ground cracked \\
\hline Mountainside Ranch, Baja & & & & 5 & & Animals frightened \\
\hline National City & 32.667 & -117.099 & 7 & 7 & 6 & Difficult to stand/walk \\
\hline Needles & 34.833 & -114.600 & 5 & 5 & 5 & Hanging objects swung, plaster cracked \\
\hline Oceanside & 33.200 & -117.383 & 6 & 6 & 4.5 & Described as strong \\
\hline Ojai & 34.449 & -119.246 & & & 1 & Not felt \\
\hline Ojos Negros, Baja & 31.900 & -116.300 & 7 & 5 & & Animals frightened \\
\hline
\end{tabular}


Table 1

Continued

\begin{tabular}{|c|c|c|c|c|c|c|}
\hline Location & Latitude $(\mathrm{N})$ & Longitude (W) & Map & Table & Rev. MMI & Most severe reported effects \\
\hline Oneonta & 32.583 & -117.117 & 7 & $6+$ & 5 & Many ran outdoors (EQ Lights reported) \\
\hline Ontario & 34.067 & -117.650 & 6 & $4+$ & 4 & Described as sharp, dishes rattled \\
\hline Otay & 32.600 & -117.067 & 7 & 7 & 7 & Masonry walls cracked \\
\hline Pacific Beach & 32.800 & -117.250 & 7 & 7 & 6 & Water waves observed \\
\hline Palm Springs & 33.817 & -116.550 & 7 & 7 & 5 & General alarm \\
\hline Paradise Valley & 33.683 & -117.067 & 7 & $6+$ & 6 & Slight damage to poor construction \\
\hline Pasadena & 34.150 & -118.150 & 5 & 5 & 5 & Described as strong, tall objects swayed \\
\hline Perris & 33.783 & -117.233 & 6 & $5+$ & 4 & Dishes rattled, awakened most \\
\hline Point Loma Lighthouse & 33.667 & -117.250 & 6 & 6 & & Duration estimated \\
\hline Pomona & 34.050 & -117.750 & 6 & 6 & 5 & Described as strong, tall objects swayed \\
\hline Potrero & 32.600 & -116.617 & 7 & 7 & 7 & Damage to weak architectural elements \\
\hline Redlands & 34.067 & -117.183 & 7 & 6 & 5 & Small objects shifted, tall objects swayed \\
\hline Redondo & 33.833 & -118.367 & 5 & 5 & 4 & Described as strong, duration estimated \\
\hline Riverside & 33.967 & -117.367 & 7 & 7 & 6.5 & Damage to weak architectural elements \\
\hline San Bernardino & 35.000 & -117.283 & 7 & 7 & 6 & Small objects overturned, damage to plaster \\
\hline San Carlos, Baja & & & 7 & $5+$ & 4.5 & Described as strong, clocks stopped \\
\hline San Diego & 32.717 & -117.167 & 7 & 7 & 6 & Masonry walls cracked \\
\hline San Felipe, Baja & 31.017 & -115.833 & & & & \\
\hline San Fernando & 34.283 & -118.433 & 5 & 5 & 4 & Described as strong, duration estimated \\
\hline San Jacinto & 33.783 & -116.967 & 7 & 6 & 6 & Liquids sloshed, plaster fell \\
\hline San Luis Rey & 33.233 & -117.200 & 6 & & & \\
\hline San Quintin, Baja & 30.500 & -115.967 & 6 & 6 & 5 & Felt by all, road subsided(?) \\
\hline San Pedro & 33.733 & -118.033 & 5 & 5 & 4 & Felt by all \\
\hline Santa Ana & 33.750 & -117.883 & 6 & 6 & 6 & Objects overturned, plaster fell \\
\hline Santa Barbara & 34.417 & -119.700 & 4 & 4 & 4 & Hanging objects swung, dishes rattled \\
\hline Santa Fe Springs & 33.950 & -118.117 & 5 & & & \\
\hline Santa Ysabel & 33.117 & -116.667 & 7 & 7 & 7 & Damage to weak architectural elements \\
\hline Storm Canyon & 32.917 & -116.433 & 8 & $7+$ & & Rockfalls \\
\hline Thing Valley Ranch & 32.817 & -116.383 & 8 & $7+$ & 7 & Difficult to stand \\
\hline Tia Juana, U.S. & 32.533 & -117.033 & 7 & & & Many ran outdoors (EQ Lights reported) \\
\hline Tijuana, Baja & 32.517 & -117.033 & 7 & 7 & & Changes in wells/springs \\
\hline Tierra Blanca Canyon & 32.900 & -116.267 & 9 & $8+$ & & Rockfalls \\
\hline Tustin & 34.733 & -117.817 & 6 & 5 & 4 & Most awakened \\
\hline Vallecitos Station & 33.983 & -116.350 & 8 & 9 & 6 & All awakened, ground cracks, all frightened \\
\hline Ventura & 34.283 & -119.283 & 4 & 4 & 4 & Hanging objects swung, clocks stopped \\
\hline Visalia & 36.317 & -119.283 & & 2 & 2 & Described as light \\
\hline Whale Peak & 33.033 & -116.317 & 9 & $7+$ & & Rockfalls \\
\hline Winchester & 33.717 & -117.083 & 6 & 4 & 3.5 & Awakened some \\
\hline Yuma, Arizona & 32.717 & -114.617 & 6 & 6 & 5 & All awakened, vibration like carriage \\
\hline
\end{tabular}

Locations at which accounts are available (town name, latitude, longitude), original MMI assignment from map in Strand (1980) and from table in same reference (these values sometimes differ), reinterpreted MMI value, brief indication of reported effects. EQ Lights indicate reports of earthquake lights.

\section{Interpretation}

Bakun and Wentworth [1997] presented a method (hereafter BW97) to determine magnitude from the distance decay of MMI values for earthquakes in western North America. This method estimates an optimal magnitude and location using observed MMI values as a function of distance and calibrations established from instrumentally recorded earthquakes in western North America. The method has been well calibrated by MMI data from a number of recent large earthquakes in California. BW97 is not a spatial contouring algorithm, but instead essentially collapses the problem to a two-dimensional regression of intensity versus distance, given established attenuation calibrations.

We first apply BW97 using the 77 reinterpreted MMI values listed in Table 1. This yields an optimal magnitude value of 7.2 and an optimal location at $32.73^{\circ} \mathrm{N}, 115.50^{\circ} \mathrm{W}$ (Fig. 3a). Interestingly, although the intensity distribution is constrained at only a few points to the south of the epicentral region, this location is very close to the northern end of the rupture mapped by Mueller and Rockwell (1995). The location is also within $15 \mathrm{~km}$ of the MMI intensity obtained using the contouring algorithm. Given the uncertainties, we do not ascribe any significance to the exact coordinates of the optimal location, specifically its location at the northern end of the mapped surface rupture.

One generally encounters a strong trade-off between location and magnitude when an intensity data set is strongly one sided; in this case most of the intensity values are from only the northwest quadrant. However, while only a handful of data values are available to the south of the (inferred) 


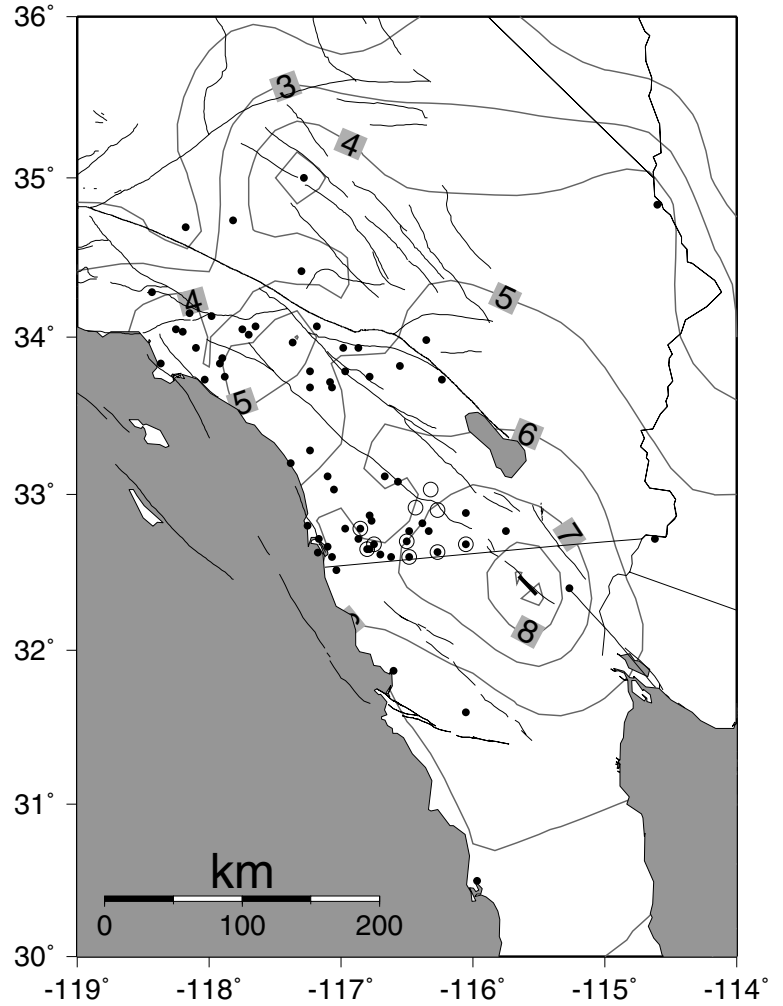

Figure 2. Locations of reinterpreted MMI values for the 1892 Laguna Salada earthquake (solid circles). Contouring is done using the Generic Mapping Tools surface algorithm; see text for details. Open circles indicate locations at which landslides or rockfalls were observed.

source location, these values apparently do provide significant constraint.

To explore the extent to which the optimal solution depends on the sparse available data to the south/southeast of the inferred epicenter, we recalculated the solution after deleting one or more of the MMI values to the south/southeast. If we delete individual values from Cerro Prieto, Ensenada, and El Alamo, or all three of these values together, all of the solutions are within the root mean square ( $\mathrm{rms})=0.2$ contour shown in Figure 3a. The one data point from Yuma, however, provides a much more important constraint. If this one data point is removed, the optimal solution shifts to $32.77^{\circ} \mathrm{N}, 114.74^{\circ} \mathrm{W}$, coincidentally very close to the location of Yuma. The optimal magnitude increases to 7.7. While one would like to have additional data points to help constrain the solution, the city of Yuma was relatively well populated, with a population of 2671 according to the 1890 census. The effects of the earthquake in Yuma were also documented by multiple accounts, all of which reveal that, while no damage occurred, the shaking was strongly felt. If we recalculate the optimal solution using an intensity value of 4 instead of the preferred value of 5, the optimal location shifts by only about $10 \mathrm{~km}$.

If we artificially impose high MMI values along the mapped trace of the Laguna Salada rupture, the optimal location shifts only slightly, to $32.41^{\circ} \mathrm{N}, 115.64^{\circ} \mathrm{W}$ (Fig. $3 \mathrm{~b}$ ). The optimal value depends on the assigned near-field MMI values: assigning values of 9 raises the $M_{\mathrm{w}}$ estimate only slightly, to 7.3 .

The extent to which historic earthquake observations can be calibrated with observations from modern events depends on the extent to which intensities have been assigned consistently for the historic and modern earthquakes. As noted, the practice of intensity assignments can vary between different individuals, and general practice has evolved somewhat over time. However, apart from detailed analysis of the intensities, a simple comparison of the 1892 intensity distribution with that from the $1992 M_{\mathrm{w}} 7.3$ Landers earthquake is illuminating (Fig. 4). We find that the overall shaking pattern is similar to that of the more recent earthquake, although the overall felt area of the Laguna Salada event appears to be somewhat smaller. The smaller felt area of the Laguna Salada earthquake might have been a consequence of the sparse population density, but southern Arizona was relatively well populated at the time. The 1887 Sonora, Mexico, earthquake was documented at dozens of locations in southern and central Arizona (DuBois and Smith, 1980). Moreover, it appears that news from southern Arizona reached the east coast more efficiently than did news from California at this time: the 1887 event received far more coverage in the New York Times than did the 1892 event. We thus settle on $M_{\mathrm{w}} 7.2$ as our preferred estimate for the 1892 event. Given the sparse intensity data, this value is probably constrained to at best \pm 0.2 .

To characterize the distance decay of MMI values from the Laguna Salada earthquake we use a least-squares regression to fit the observed values to the equation

$$
\mathrm{MMI}=A-B r-C \log (r),
$$

where $A, B$, and $C$ are constants and $r$ is epicentral distance. The optimal curve $(A=12.8, B=0.0039, C=3.0)$ is shown in Figure 4 . The open circles along this curve correspond to the rockfall locations shown in Figure 1. At some of these locations we are not able to estimate MMI values, whereas estimated values at other locations are relatively poorly constrained. The circles thus indicate estimated shaking intensity levels at locations at which rockfalls were observed. Although preliminary, these results suggest that rockfalls are typically generated by shaking levels of MMI VI and higher.

Fitting equation (1) to the Landers MMI values, we obtain $A, B$, and $C$ values of $12.6,0.00006$, and 3.47, respectively. Although these values, and the curve shown in Figure 4, differ from those obtained for the Laguna Salada earthquake, Figure 4 reveals that the distance decay of the curve for the Landers earthquake is strongly controlled by weakly felt reports at large (900-1200 km) distance. The lack of similar values for the Laguna Salada earthquake might re- 
(a)

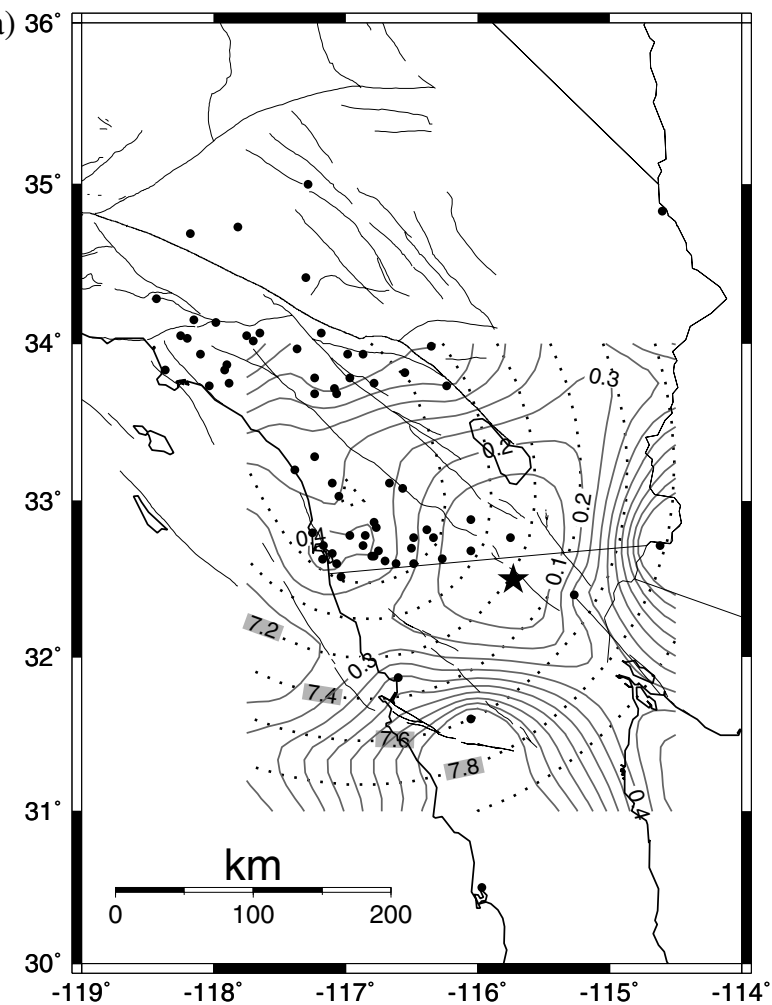

(b)

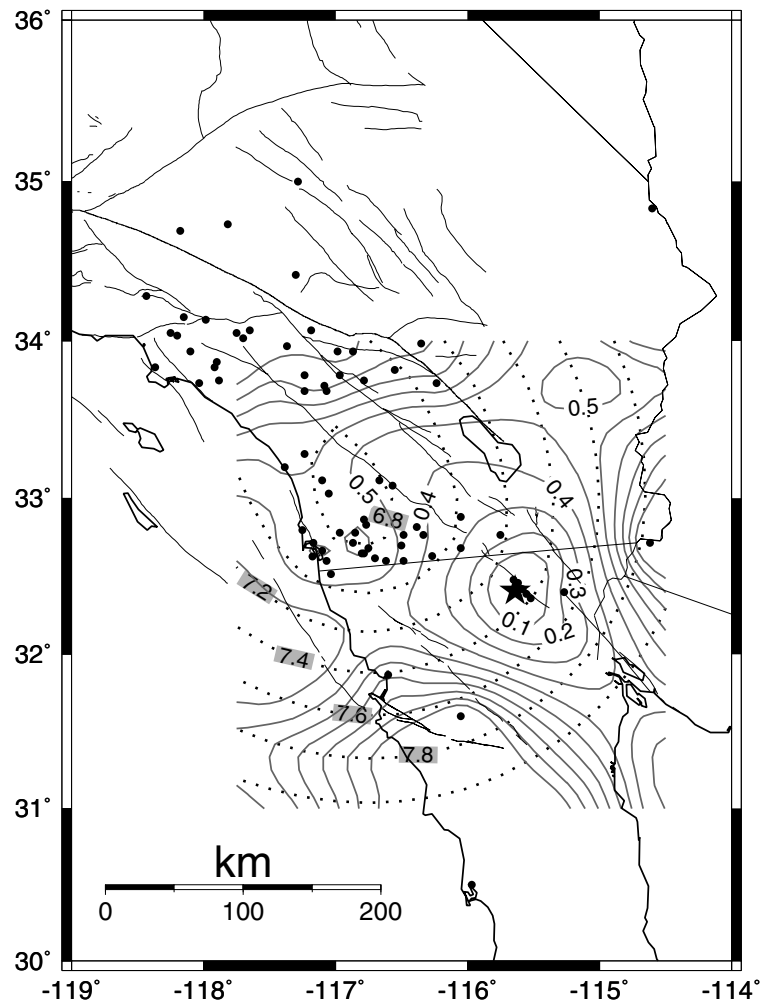

Figure 3. (a) The reinterpreted intensity distribution and results of grid-search regression for optimal location and magnitude using the method of Bakun and Wentworth (1997). The rms misfit value and magnitude results over the grid of trial locations are contoured with solid and dotted lines, respectively. (b) The regression results when high intensity values are artificially imposed along the trace of the mapped Laguna Salada fault rupture.

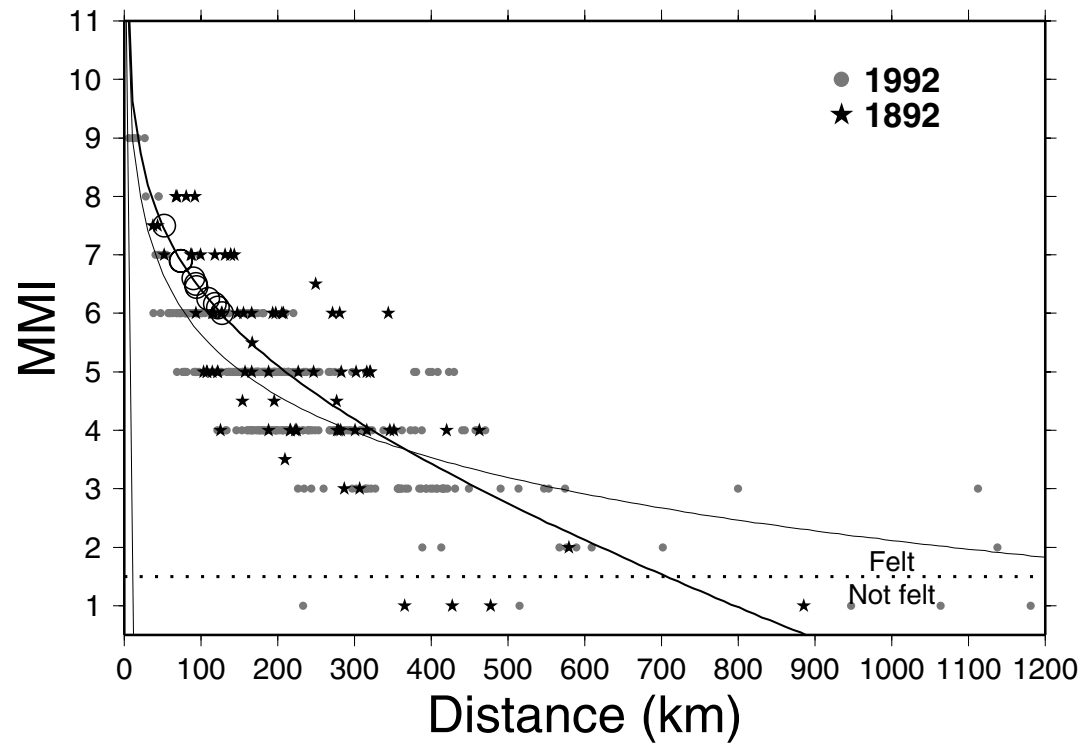

Figure 4. The shaking distributions of the 1992 Landers is shown along with that from the 1892 Laguna Salada earthquake. For both events, distance is estimated as the nearest distance to the mapped surface rupture. Heavy solid line shows best-fitting curve fit to Laguna Salada MMI values; light solid line shows bestfitting curve fit to Landers values. Open circles along this line indicate distances at which landslides and rockfalls were observed. flect either the slightly smaller size of the event or its more sparse data set.

The intensity distributions of the 1892 and 1992 earthquakes reveal elongation of contours to the northwest-southeast; a similar pattern was observed for the 1999 Hector
Mine earthquake (see the archives of http://pasadena.wr. usgs.gov/shake/ca/index.html). This pattern is suggestive of rupture directivity for the Landers and Laguna Salada earthquakes. The former event is known to have had strong alongstrike directivity, and the latter event could have also rup- 
tured toward the north-northwest. However, the Hector Mine rupture was largely bilateral and was not associated with strong directivity. We speculate that the similar pattern may in part reflect more efficient wave propagation in the direction of the regional tectonic fabric.

Large-scale anisotropy of wave propagation has been suggested and/or observed in previous studies. Kennett (1984) demonstrated that the development of higher-mode crustal surface waves is affected by large-scale crustal structure. This work was developed in subsequent theoretical studies (e.g., Kennett, 1986) and confirmed in observational investigations of $\mathrm{Lg}$ propagation (e.g., Hough et al., 1989; Baumgardt, 1990; Wald and Heaton, 1991; McNamara et al., 1996). In northern Baja California and southern California, the prevailing southeast-northwest trend of major batholiths and other structures is thus expected to be associated with especially efficient regional wave propagation. $L g$ propagation would be less efficient to the northeast of the mainshock, in which direction surface wave development would be impeded by large-scale crustal heterogeneity, including the presence of large sedimentary basins. As a rule, large sedimentary basins are associated with the amplification of ground motions, but where such basins interfere with the development of higher-mode surface waves, the result will be stronger apparent attenuation.

\section{Conclusions}

The results presented in this brief study show that a reinterpretation of the intensity data from the 1892 earthquake yields a magnitude estimate significantly below that previously inferred from the same felt reports considered in this study. Our preferred estimate, $M_{\mathrm{w}} 7.2$, is very close to the value estimated based on the length of the Laguna Salada rupture (Mueller and Rockwell, 1995).

The earthquake thus appears to be similar in magnitude to the recent 1992 Landers and 1999 Hector Mine earthquakes. Combining this result with the reinterpreted magnitudes for the 1811-1812 New Madrid earthquakes (Hough et al., 2000), one finds the 1857 Fort Tejon and 1906 San Francisco earthquakes to be nearly in a class by themselves among (crustal) events in the contiguous United States, with the 1872 Owens Valley earthquake (estimated $M_{\mathrm{w}}$ 7.6) third on the list.

Even without reliable intensity observations for the epicentral region, the macroseismic effects are sufficiently dense to yield an optimal location in northern Baja California, very close to the Holocene surface rupture mapped by Mueller and Rockwell (1995). Our results are based on an intensity distribution that is largely one sided, so the intensities alone are not sufficient to constrain the location precisely. However, even the sparse data to the south and southeast represent an improvement over the situation with many important historic earthquakes (those along coastlines, as well as the 1811-1812 New Madrid sequence), for which the intensity distributions are entirely one sided. Our results thus corroborate the earlier association of the Laguna Salada rupture with the 1892 earthquake, as well as the Mueller and Rockwell (1995) estimate of magnitude.

In our study we have used two approaches to identify the location of an earthquake from an intensity distribution: that of Bakun and Wentworth (1997) and a simple contouring algorithm. In this case the results are found to be extremely consistent. In general we anticipate that the two methods might be complementary, as the former method incorporates attenuation based on observations, while the latter considers the two-dimensional distribution of data.

\section{Acknowledgments}

We thank Erdal Safak, Greg Anderson, Karl Mueller, Ken Hudnut, and Nick Ambraseys for helpful comments and suggestions. We also thank Ruth Ludwin for a careful and constructive review. Figures 2-4 were generated using GMT software (Wessel and Smith, 1991).

\section{References}

Ambraseys, N., and R. Bilham (2003). Reevaluated intensities for the great Assam earthquake of 12 June 1897, Shillong, India, Bull. Seism. Soc. Am. 93, 655-673.

Bakun, W. H., and C. M. Wentworth (1997). Estimating earthquake location and magnitude from seismic intensity data, Bull. Seism. Soc. Am. 87, 1502-1521.

Barnard, F. L. (1968). Structural geology of the Sierra de Los Cucapas, northeastern Baja California, Mexico, and Imperial County, California, Ph.D. Thesis, University of Colorado, Boulder, Colorado.

Baumgardt, D. R. (1990). Invesigation of teleseismic $L G$ blockage and scattering using regional arrays, Bull. Seism. Soc. Am. 80, 2261-2281.

Brazee, R. J. (1979). Re-evaluation of modified Mercalli intensity scale for earthquakes using distance as determinant, Bull. Seism. Soc. Am. 69, 911-924.

DuBois, S. M., and A. W. Smith (1980). The 1887 earthquake in San Bernardino Valley, Sonora: historic accounts and intensity patterns in Arizona, State of Arizona Bureau of Geol. and Mineral Tech., Special Paper 3.

Hough, S. E., K. Jacob, and P. Friberg (1989). The 11/25/1988 M6 Saguenay earthquake near Chicoutimi, Quebec: evidence for anisotropic wave propagation in northeastern North America, Geophys. Res. Lett. 16, 645-648.

Hough, S. E., J. G. Armbruster, L. Seeber, and J. F. Hough (2000). On the modified Mercalli intensities and magnitudes of the 1811-1812 New Madrid, central United States earthquakes, J. Geophys. Res. 105, 23,839-23,864.

Jennings, C. W. (1994). Fault activity map of California and adjacent areas, Calif. Geol. Survey GDM 6.

Kennett, B. L. N. (1984). Guided wave-propagation in laterally varying media. 1. Theoretical development, Geophys. J. R. Astr. Soc. 79, 235255.

Kennett, B. L. N. (1986). Lg-waves and structural boundaries, Bull. Seism. Soc. Am. 76, 1133-1141.

McNamara, D. E., T. J. Owens, and W. R. Walter (1996). Propagation chraracteristics of $L g$ across the Tibetan Plateau, Bull. Seism. Soc. Am. 86, 457-469.

Mueller, K. J., and T. K. Rockwell (1995). Late Quaternary activity of the Laguna Salada fault in northern Baja California, Mexico, Geol. Soc. Am. Bull. 107, 8-18.

Musson, R. M. W. (1998). The Barrow-in-Furness earthquake of 15 February 1865: liquefaction from a very small magnitude event, Pure Appl. Geophys. 152, 733-745. 
Strand, C. L. (1980). Pre-1900 earthquakes of Baja California and San Diego County, San Diego State University, Master's Thesis, San Diego, California, 320 pp.

Toppozada, T. R., C. R. Real, and D. L. Parke (1981). Preparation of isoseismal maps and summaries of reported effects of pre-1900 California earthquakes: California Division of Mines and Geology, OpenFile Report 81-11.

Wald, L. A., and T. H. Heaton (1991). $L G$ waves and $R G$ waves on the California regional networks from the December 23, 1985 Nahanni earthquake, J. Geophys. Res. 96, 12,099-12,125.

Wald, D. J., V. Quitoriano, T. H. Heaton, and H. Kanamori (1999). Relationships between peak ground acceleration, peak ground velocity, and modified Mercalli intensity in California, Earthquake Spectra 15, $557-564$.
Wessel, P., and W. H. F. Smith (1991). Free software helps map and display data, $\operatorname{EOS} \mathbf{7 2}, 441,445$.

U.S. Geological Survey

Pasadena, California 91106

(S.E.H.)

South Pasadena High School

South Pasadena, California 91030

(A.E.)

Manuscript received 8 December 2003. 